\title{
The Inheritance of Penicillin Titre in Wild-type Isolates of Aspergillus nidulans
}

\author{
By M. J. MERRICK* AND C. E. CATEN \\ Department of Genetics, University of Birmingham, BI5 $2 T T$
}

(Received 26 June 1974; revised 2 September 1974)

\begin{abstract}
SUMMARY
In a sample of 52 wild-type isolates of Aspergillus nidulans, penicillin titre ranged from 0.0 to 14.4 units $/ \mathrm{ml}$. These differences in titre were under genetic control. Most of the variation between isolates was attributable to differences between heterokaryon-compatibility groups although significant differences were also found within groups. Genetic variation for penicillin titre was observed among the progeny in four of seven crosses between wild-type isolates. In these four crosses the variation was continuous, indicating that this is a polygenically determined character, and progeny with titres superior and inferior to those of the parents were produced. The genes determining penicillin production are predominantly additive in their action. Crosses between heterokaryon-incompatible isolates generated more genetic variation than those involving compatible parents, supporting the hypothesis that heterokaryon-compatible isolates are frequently closely related.
\end{abstract}

\section{INTRODUCTION}

The production of penicillin-like substances by isolates of Aspergillus nidulans was first reported by Foster \& Karrow (I945) and subsequently Dulaney (I947) demonstrated variation in productivity amongst a number of isolates from culture collections. The extensive genetic knowledge of $A$. nidulans which has since been accumulated (Pontecorvo et al. I953; Käfer, I958; Pontecorvo \& Käfer, I958; Dorn, I967) makes it a very suitable organism in which to study the genetics of penicillin production.

Holt \& Macdonald (I968a) showed that the antibiotic produced by five independent isolates and two mutant derivatives of $A$. nidulans was indistinguishable from penicillin, and a heterokaryon test between two mutant strains indicated that antibiotic productivity was under nuclear control. Sexual crosses were then carried out between different wild-type isolates (Holt \& Macdonald, I968 $b$ ) and recombinant progeny were obtained with increased penicillin titres. In a discussion of their work, Holt \& Macdonald (I968a) suggested that a study of the quantitative inheritance of penicillin production could now be undertaken.

The experiments discussed form part of studies on the inheritance of penicillin production in wild-type isolates of $A$. nidulans. The range of variation for penicillin titre and the genetic determination of titre have been investigated using biometrical techniques.

\section{METHODS}

Strains. The 52 wild-type isolates of the Aspergillus nidulans group (Raper \& Fennel, 1965) were isolated from soil samples taken from various regions of England and Wales. Stock cultures of all strains used were produced from single ascospore isolates. Thirty-one

* Present address: Department of Genetics, John Innes Institute, Colney Lane, Norwich NR4 UH. 
of these isolates have been allocated to heterokaryon-compatibility (h-c) groups (Grindle, I $963 a$; J. H. Croft, personal communication). The remaining $2 \mathrm{I}$ isolates either are not compatible with any of the 20 groups which are at present recognized in the Birmingham collection, or have not been tested. Heterokaryon formation between pairs of wild-type isolates is restricted to members of the same h-c group (Grindle, I963 b) but sexual outcrossing is possible between all wild-type isolates to a greater or lesser extent, regardless of heterokaryon incompatibility (Butcher, 1968).

Stock cultures were maintained as dry conidia on silica-gel crystals at $4{ }^{\circ} \mathrm{C}$ (Roberts, 1969). When in use, strains were incubated for five days at $35^{\circ} \mathrm{C}$ on slopes of $2 \%(\mathrm{w} / \mathrm{v})$ malt extract agar in Universal bottles and then maintained at $4{ }^{\circ} \mathrm{C}$.

Media. Czapek agar $(\mathrm{CZ})$ was used as the basic medium for routine transfers and crossing. To reduce colony size, conidia and ascospore suspensions were plated on $\mathrm{CZ}$ containing sodium desoxycholate (BDH) at $\mathrm{I} \cdot 2 \mathrm{mg} / \mathrm{ml}$; this medium is called CZD. Malt extract agar $(2 \%, w / v)$ was used as a conidiation medium for the preparation of inoculum for the shake flask fermentations. Spore suspensions were prepared in a solution of $0.02 \%(\mathrm{v} / \mathrm{v})$ ' Calsolene' oil (I.C.I. Ltd). The fermentation medium for penicillin production was that given by Macdonald, Hutchinson \& Gillett (1963). It was dispensed in $40 \mathrm{ml}$ amounts into $250 \mathrm{ml}$ Erlenmeyer flasks which were then plugged with disposable foam bungs and autoclaved for I $5 \mathrm{~min}$ at $100 \mathrm{kN} / \mathrm{m}^{2}$ ( $15 \mathrm{lbf} / \mathrm{in}^{2}$ ). The medium used for the biological assay had the following composition: sodium citrate, $10.0 \mathrm{~g}$; Oxoid peptone, $5.0 \mathrm{~g}$; Lab. Lemco, 3.0 g.; agar (Oxoid No. 3), 12.0 g; distilled water to I 1.

Crossing technique. All crosses were carried out by single perithecium analysis (Pontecorvo et al. 1953) using, as parents, a green-spored prototroph and a yellow-spored prototroph. (Spore colour mutations were induced by ultraviolet irradiation of wild-type conidial suspensions.) Portions ( $\mathrm{I} \mathrm{ml}$ ) from a dense conidial suspension $\left(10^{7}\right.$ to $10^{8}$ conidia $\left./ \mathrm{ml}\right)$ of each parent were mixed and $0^{\circ} \mathrm{I} \mathrm{ml}$ was spread on to $\mathrm{CZ}$. The plates were incubated at $35^{\circ} \mathrm{C}$ for Io to I 4 days by which time mature perithecia were usually present. Individual perithecia were sampled from the crossing plate and transferred to a plate of $\mathrm{CZ}$. They were stripped of Hülle cells and conidia by rolling them across the surface of the agar using a glass needle with a rounded tip. Cleaned perithecia were then broken between two glass needles on a fresh $\mathrm{CZ}$ plate and their walls removed. To select hybrids, a sample of ascospores from each perithecium was point-inoculated on to $\mathrm{CZ}$ and incubated at $35^{\circ} \mathrm{C}$ for three days. The remaining ascospores were stored on the plates at $4{ }^{\circ} \mathrm{C}$. Ascospore samples from hybrid perithecia produced colonies showing a mixture of both spore colours in approximately equal proportions. When a perithecium had been selected in this way a further sample of ascospores was transferred from the stored plate to $0^{\circ} \mathrm{I} \mathrm{ml}$ of 'Calsolene' oil on CZD, and spread. After incubation for three days at $35{ }^{\circ} \mathrm{C}, 50$ colonies were selected at random for antibiotic yield testing.

Antiobiotic yield testing. Strains were inoculated on to $2 \%$ malt agar slopes in Universal bottles and incubated at $35{ }^{\circ} \mathrm{C}$ for five or six days. Six $\mathrm{ml}$ 'Calsolene' oil were added to each slope culture and the conidia were suspended therein by placing the bottle on a vortex mixer. The contents of the bottle were then tipped quickly into a flask. Flasks were arranged in a single randomized block on one shelf of a rotary shaker and incubated for a period of four to six days at $26^{\circ} \mathrm{C}$. The shaker had a 2 in throw and ran at $220 \mathrm{rev} . / \mathrm{min}$.

Shake flask broths were filtered through Whatman No. 54 paper and the filtrate (diluted if necessary) was used for assay. The assay was carried out on $30.5 \times 30.5 \mathrm{~cm}(\mathrm{I} 2 \times 12$ in) assay plates constructed according to the methods of Lees \& Tootill (I955). A suspension of pasteurized Bacillus subtilis (ATCC6633) spores was added to $250 \mathrm{ml}$ of molten assay 
medium at 50 to $60{ }^{\circ} \mathrm{C}$ (final concentration $\mathrm{I} \cdot 5 \times 10^{6}$ spores $/ \mathrm{ml}$ agar). The plates were sterilized by wiping with ethanol and flaming, and then levelled before the medium was poured. Wells were cut in the agar in an $8 \times 8$ arrangement and the samples applied as described by Brownlee, Loraine \& Stephens (1949). Of the 64 wells on each plate, 52 were filled with unknown samples and the remaining 12 were used for standard benzyl penicillin solutions at concentrations of 2 units $\mathrm{ml}(\mathrm{u} / \mathrm{ml}), \mathrm{I} \mathrm{u} / \mathrm{ml}$ and $0.5 \mathrm{u} / \mathrm{ml}$, each concentration being replicated in four wells. The plates were incubated overnight at $30^{\circ} \mathrm{C}$ and the diameters of the developed inhibition zones were measured in the manner described by Lees $\&$ Tootill (1955).

Where a number of replicate flasks were assayed for each strain, each replicate was assigned to a different plate. Hence, when 52 strains were assayed using two flasks per strain, two plates were used and each strain was represented once on each plate. The 52 strains and the $\mathrm{I} 2$ standards were allocated to positions on the assay plate in a completely random manner.

The conversion of zone diameters to units of penicillin was carried out using a Wang 600 Advanced Programmable Calculator. The diameters of the zones produced by the three penicillin standards were used to calculate a regression of zone diameter on log concentration for each assay plate. The observed zone diameters of the unknown samples were then converted to titres using this regression equation. The machine was also programmed to take account of any dilution of the sample before it was assayed so that the result was given in terms of the titre produced in each flask. This method of calculation was found to be faster than alternative graphical methods, and also avoided the errors inherent in fitting and reading from a regression line.

\section{RESULTS \\ Primary screen of wild isolates}

Fifty-two isolates were chosen at random from the Birmingham collection and were assayed twice for penicillin production, one flask being used on each occasion. The productivity of the isolates (Fig. I) ranged from $0.0 \mathrm{u} / \mathrm{ml}$ to I $4.4 \mathrm{u} / \mathrm{ml}$ with a mean of $8.0 \pm 0.4 \mathrm{u} /$ $\mathrm{ml}$. An analysis of variance (Table $\mathrm{I}$ ) shows that the differences between isolates are highly significant. The mean titre in the first experiment $(6.47 \pm 0.35 \mathrm{u} / \mathrm{ml})$ was significantly lower than that in the second $(9 \cdot 35 \pm 0.54 \mathrm{u} / \mathrm{ml})$. This was probably due to a breakdown of the rotary shaker in the first experiment approximately $4 \mathrm{~h}$ before the flasks were assayed. The significant differences between the isolates suggest that there are genetic differences between them, and the normal frequency distribution (Fig. I) indicates that penicillin production is a continuously varying character.

Three of the isolates tested gave yields of less than $0.5 \mathrm{u} / \mathrm{ml}$; one of these was an isolate of Aspergillus quadrilineatus (Birmingham No. 12); one was Aspergillus nidulans var. echinulatus (Birmingham No. 25) and one was a member of h-c group F (Birmingham No. 136). This last result agrees with those of Holt \& Macdonald (I968a) who stated that members of h-c groups $\mathrm{F}$ and $\mathrm{G}$ had no detectable antibiotic activity. Information concerning compatibility was available for $3 \mathrm{I}$ isolates of the present sample. Table 2 shows an analysis of variance in which the sum of squares for these 3I isolates has been partitioned into an item to test for differences between h-c groups and a remainder which tests for variation within the h-c groups. Although there are significant differences in penicillin production both between and within h-c groups, estimates of the components of variation indicate that $67 \%$ of the differences between isolates are due to differences between h-c groups. Holt \& Macdonald 


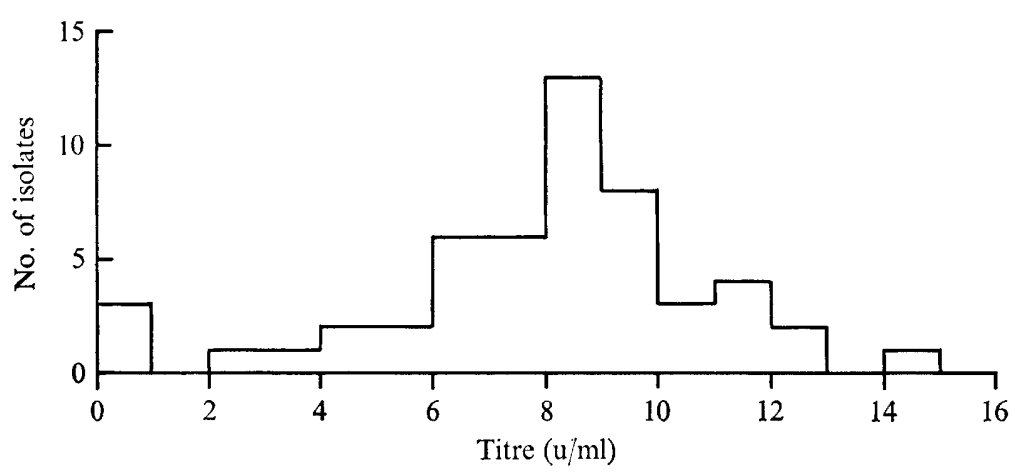

Fig. I. Penicillin titres of 52 wild-type isolates of Aspergillus nidulans. Mean of two occasions with one flask on each.

Table I. Analysis of variance of penicillin titre on two occasions for a random sample of 52 wild-type isolates of Aspergillus nidulans

$\begin{array}{lccc} & \text { Degrees of freedom } & \text { Mean square } & \text { Variance ratio } \\ \text { Between isolates } & 5 \text { I } & \text { I7.4I } & 4 \cdot 14^{*} \\ \text { Between occasions } & \text { I } & 244 \cdot 00 & 57^{*} 97^{*} \\ \text { Isolates } \times \text { occasions } & 5 \text { I } & 4.2 \text { I } & - \\ & * \text { Significant at } P=0.00 \mathrm{I} .\end{array}$

Table 2. Analysis of variance of penicillin titre for those isolates (3I) in known heterokaryon compatibility groups

\begin{tabular}{lrrc} 
& Degrees of freedom & Mean square & Variance ratio \\
Between h-c groups & 9 & 36.40 & $4.19^{*}$ \\
Within h-c groups & $2 \mathrm{I}$ & 8.68 & $2 \cdot 26 \dagger$ \\
Occasions & $\mathrm{I}$ & 179.86 & $46.73 \ddagger$ \\
Isolates $\times$ occasions & 30 & 3.85 & - \\
\multicolumn{1}{c}{$* P=0.01$ to $0.00 \mathrm{I}}$. & $\dagger P=0.05$ to $0.0 \mathrm{I} . \quad \ddagger P=0.00 \mathrm{I}$.
\end{tabular}

(1968a) concluded that strains giving high penicillin yields were not members of any particular group. However, the detection of significant differences between h-c groups indicates that some groups have a higher average yield than others and that it is possible to rank them in order of mean titre (Table 3). In this way some distinction may be made between 'high' and 'low' titre groups.

\section{Crosses}

To confirm that the titre differences between isolates, detected in the primary screen, were genetically determined and to examine the nature of the genetic control, eight crosses were made between pairs of wild-type isolates and the titres of a sample of single ascospore cultures from each cross determined (Table 4). Following Butcher (1969), the haploid single ascospore progeny produced by crossing two haploid parent strains will be referred to as an $F_{1}$ generation. The eight crosses fell into five classes as follows: (i) between 'high' titre, heterokaryon-compatible isolates (h.c.), crosses $\mathrm{MI}_{\mathrm{I}}$ and $\mathrm{M2}$; (ii) between 'high' titre, heterokaryon-incompatible isolates (h.i.), crosses $\mathrm{M}_{3}, \mathrm{M}_{4}$ and $\mathrm{M}_{5}$; (iii) between 'low' titre, heterokaryon-compatible isolates (l.c.), cross M40; (iv) between 'low' titre, hetero- 
Table 3. Mean penicillin titre of ten heterokaryon-compatibility groups

$\begin{array}{ccc}\text { h-c group } & \text { No. of isolates } & \text { Titre }(\mathrm{u} / \mathrm{ml}) \\ \text { I } & \text { I } & 12 \cdot 7 \\ \text { H } & 3 & 11 \cdot 6 \\ \text { E } & 2 & 9 \cdot 6 \\ \text { R } & \text { I } & 9 \cdot 4 \\ \text { A } & 8 & 9 \cdot 2 \\ \text { B } & 9 & 7 \cdot 9 \\ \text { L } & \text { I } & 7 \cdot 6 \\ \text { C } & 3 & 6 \cdot 2 \\ \text { K } & 2 & 4 \cdot 8 \\ \text { F } & \text { I } & 0 \cdot 2\end{array}$

Values are the means of the titres for those isolates belonging to a known compatibility group. The titre of each isolate was determined on two occasions with one flask on each.

Table 4. Parental strains, number of progeny sampled and degree of replication for penicillin titre comparisons among progeny from eight crosses between wild-type isolates of $A$. nidulans

\begin{tabular}{|c|c|c|c|c|}
\hline $\begin{array}{l}\text { Type of } \\
\text { cross* }\end{array}$ & Cross no. & $\begin{array}{c}\text { Parents } \dagger \\
\mathbf{P}_{1} \times \mathbf{P}_{2}\end{array}$ & $\begin{array}{l}\text { No. of } \\
\text { progeny } \\
\text { sampled }\end{array}$ & $\begin{array}{l}\text { No. o } \\
\text { replica } \\
\text { flasks }\end{array}$ \\
\hline \multirow[t]{2}{*}{ h.c. } & MI & $109 / 1 \times 65$ & 50 & 4 \\
\hline & M2 & I I I $\times 65 / 1$ & 50 & 4 \\
\hline \multirow[t]{3}{*}{ h.i. } & M3 & $159 \times 13 I / I$ & 50 & 2 \\
\hline & M4 & $183 \times 189 / 1$ & 50 & 2 \\
\hline & M5 & $139 \times 82 / 1$ & 50 & 2 \\
\hline 1.c. & $\mathrm{M}_{40}$ & $134 \times 176 / I$ & 44 & 2 \\
\hline l.i. & $\mathrm{M}_{4 \mathrm{I}}$ & $154 \times 176 / 1$ & 44 & 2 \\
\hline h.s. & $\mathrm{M}_{42}$ & $65 \times 65$ & 50 & 4 \\
\hline
\end{tabular}

* h., l., 'High' and 'low' titre respectively; c., i., heterokaryon-compatible and -incompatible parents respectively; h.s., selfing of a high-titre strain.

$\dagger-/ \mathrm{I}$, Yellow-spored mutant of wild isolate -.

Table 5. Standard analysis for variation in penicillin titre among samples of progeny from a single cross

\begin{tabular}{lcl} 
Between progeny & $\begin{array}{c}\text { Degrees of } \\
\text { freedom* }\end{array}$ & \multicolumn{1}{c}{$\begin{array}{c}\text { Expected mean } \\
\text { square }\end{array}$} \\
Between spore colours & $\mathrm{I}$ & $\sigma_{E}{ }^{2}+p \sigma_{G}{ }^{2}+p n_{0} \sigma_{\theta}{ }^{2} \dagger$ \\
Within spore colours & $s-2$ & $\sigma_{c}{ }^{2}+p \sigma_{\theta}{ }^{2}$ \\
Between plates & $p-\mathrm{I}$ & $\sigma_{E}{ }^{2}+s \sigma_{P}{ }^{2}$ \\
Plates $\times$ progeny & $(s-\mathrm{I})(p-\mathrm{I})$ & $\sigma_{E}{ }^{2}$ \\
Total & $s p-\mathrm{I}$ &
\end{tabular}

* $s$, No. of progeny strains; $p$, no. of replicate assay plates.

$\dagger n_{0}$, Weighted average of the number of strains of each conidial colour, calculated from

(Snedecor \& Cochran, 1967).

$$
n_{0}=\frac{\mathrm{I}}{a-\mathrm{I}}\left(N-\frac{n_{\mathrm{i}}^{2}}{N}\right)
$$

karyon-incompatible isolates (l.i.), cross $\mathrm{M}_{4} \mathrm{I}$; (v) progeny from a selfed perithecium (h.s.), cross $\mathrm{M}_{42}$.

An analysis of variance was carried out on the progeny titres from each cross using the standard form shown in Table 5. In each cross (except M42) the progeny were segregating for the yellow conidial colour marker $y$ and the 'between progeny' item in the analysis can 
be divided into a 'between spore colours' item for I degree of freedom (d.f.), which measures the variation associated with this marker, and a 'within spore colours' item which measures the variation among progeny strains of the same colour resulting from the segregation of natural allelic differences affecting penicillin titre. From the expected mean squares in this analysis four components of variation can be estimated: (i) ${\sigma_{E}}^{2}$ is a measure of the environmental variation and includes all items which contribute to variation between replicate flasks of the same strain, except differences between assay plates; (ii) $\sigma_{P}{ }^{2}$ is a measure of the variation between assay plates; (iii) $\sigma_{c}{ }^{2}$ is a measure of the variation associated with the spore colour marker; (iv) $\sigma_{G}{ }^{2}$ is a measure of the variation due to segregation of natural allelic differences affecting penicillin titre.

For each cross, the proportion of the total variation, excluding that between assay plates which is common to all genotypes, that was genetically determined was calculated as:

$$
h^{2}=\frac{\sigma_{G}^{2}}{\sigma_{G}^{2}+\sigma_{E}^{2}} .
$$

This corresponds to a heritability for observations of progeny penicillin titres derived from single determinations on single flasks. The variation associated with the spore colour marker $\left(\sigma_{o}^{2}\right)$ has been ignored in this calculation since, although it is genetic and could be fixed, it was not present in the original isolates.

Data from each cross were also examined to determine whether the segregating penicillin genes were acting in an additive or non-additive manner. In haploid organisms all nonadditive variation must arise through epistasis. Comparison of the mid-parental value and the mean progeny value therefore provides a direct test for epistatic variation with a directional component (Butcher, I969; Mather \& Jinks, I971). The deviation of the mean progeny value from the mid-parental value gives an estimate of the contribution of gene interaction effects ([i]) to the mean phenotype. These estimates were tested for significance from zero using a ' $t$ ' test.

Significant variation in penicillin titre was detected in four of the eight crosses (Table 6). Three of these ( $\mathrm{M}_{4}, \mathrm{M}_{5}$ and $\mathrm{M}_{4} \mathrm{I}$ ) involved heterokaryon-incompatible parents and the other $\left(\mathrm{MI}_{\mathrm{I}}\right)$ involved heterokaryon-compatible parents. In the other four crosses no significant differences between progeny were detected. One of these $\left(\mathrm{M}_{42}\right)$ was a self and may be considered as a control with the expectation of no segregation; two (M2 and M40) were crosses between compatible isolates, and one $\left(\mathrm{M}_{3}\right)$ a cross between incompatible isolates. In all cases the frequency distribution for the progeny was continuous and approximately normal (Fig. 2). No indication of segregation of major genes affecting titre was found. In all those crosses showing segregation, progeny were obtained with titres significantly higher or significantly lower than those of the parents. Progeny with no detectable activity were obtained from $\mathrm{M}_{5}$, and in MI one recombinant had a titre of $2 \mathrm{I} \cdot 5 \mathrm{u} / \mathrm{ml}$, almost twice that of the parent strains. Estimates of heritability (Table 6) for the crosses showing segregation ranged from 38 to $77 \%$, reflecting variation in the degree of heterozygosity from one cross to another.

In only two crosses (MI and M2) was there evidence for the presence of non-allelic interactions, i.e. [ $i$ ] significantly different from zero (Table 6). The result of $\mathrm{M}_{2}$ is anomalous, as the analysis of variance indicates no segregation in this cross. Therefore, with the exception of MI, the gene action appears to be predominantly additive and this can be clearly seen from the symmetrical distribution of the progeny titres about a value close to the parental mean (Fig. 2). For MI, in which epistasis was detected, the progeny mean is higher than the parental mean indicating the presence of titre-decreasing interactions in the parents. 

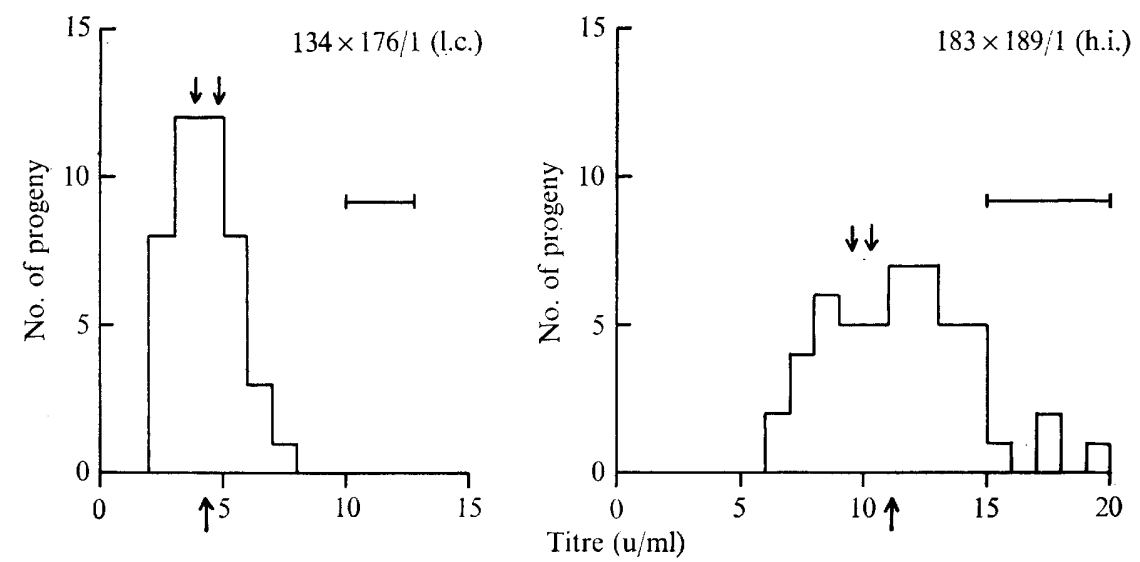

Fig. 2. Penicillin titre of samples of single ascospore progeny from two crosses between wild-type isolates. Mean of two flasks. $\uparrow$, Progeny mean titre; $\downarrow$, parental titres; $\mapsto$, least significant difference $5 \%$.

Table 6. Summary of data for the inheritance of penicillin production in eight crosses between wild-type isolates of $A$. nidulans

\begin{tabular}{|c|c|c|c|c|c|c|c|c|c|c|c|}
\hline \multirow{2}{*}{$\begin{array}{l}\text { Type } \\
\text { of } \\
\text { cross }\end{array}$} & \multirow[b]{2}{*}{$\begin{array}{c}\text { Cross } \\
\text { no. }\end{array}$} & \multicolumn{2}{|c|}{$\begin{array}{l}\text { Parental } \\
\text { mean titre* } \\
(\mathrm{u} / \mathrm{ml})\end{array}$} & \multirow{2}{*}{$\begin{array}{c}\text { Progeny } \\
\text { mean } \\
\text { titre } \\
(\mathrm{u} / \mathrm{ml}) \\
F_{1}\end{array}$} & \multirow{2}{*}{$\begin{array}{l}\text { Progeny } \\
\text { range } \\
(\mathrm{u} / \mathrm{ml})\end{array}$} & \multirow[b]{2}{*}[i]{} & \multirow[b]{2}{*}{$\begin{array}{c}\bar{x}_{g} \\
(\mathrm{u} / \mathrm{ml})\end{array}$} & \multirow[b]{2}{*}{$\begin{array}{c}\bar{x}_{y} \\
(\mathrm{u} / \mathrm{ml})\end{array}$} & \multirow[b]{2}{*}{$\hat{\sigma}_{G i}^{2}$} & \multirow[b]{2}{*}{$\hat{\sigma}_{E^{2}}{ }^{2}$} & \multirow[b]{2}{*}{$h^{2}$} \\
\hline & & $P_{1}$ & $\overrightarrow{P_{2}}$ & & & & & & & & \\
\hline h.c. & MI & I I $\cdot 8$ & $10 \cdot 4$ & 14.6 & $7 \cdot 4-2 \mathrm{I} \cdot 5$ & $-3.47 \dagger$ & 15.01 & 14.09 & 10.02 & I I 45 & $0.47 \dagger$ \\
\hline & M2 & 12.6 & I I $\cdot 8$ & 13.9 & $10.9-16.4$ & $-I \cdot 77^{\dagger}$ & 14.58 & $13 \cdot 24 \ddagger$ & 0.35 & 5.02 & 0.07 \\
\hline h.i. & $\mathrm{M}_{3}$ & $7 \cdot 9$ & $5 \cdot 3$ & $6 \cdot 7$ & $3 \cdot 9-11 \cdot 7$ & -0.13 & $7 \cdot 43$ & $6 \cdot 09 \ddagger$ & 0.23 & $3 \cdot 38$ & 0.06 \\
\hline & $\mathrm{M}_{4}$ & $10 \cdot 3$ & $9 \cdot 5$ & II $\cdot I$ & $4 \cdot 2-19 \cdot 2$ & $-I \cdot 23$ & $12 \cdot 58$ & $10.35 \ddagger$ & $3 \cdot 84$ & $6 \cdot 36$ & $0.38 \dagger$ \\
\hline & M5 & $9 \cdot 6$ & $4 \cdot 2$ & $6 \cdot I$ & $0.0-18.9$ & 0.75 & 6.53 & $5 \cdot 72$ & 15.43 & $11 \cdot I 5$ & $0.58 \dagger$ \\
\hline 1.c. & $\mathrm{M}_{40}$ & $4 \cdot 8$ & $3 \cdot 8$ & $4 \cdot 3$ & $2 \cdot 7-7 \cdot 2$ & -0.02 & $5.0 \mathrm{I}$ & $3.60 t$ & 0.00 & $1 \cdot 98$ & 0.00 \\
\hline l.i. & $\mathrm{M}_{4 \mathrm{I}}$ & $5 \cdot I$ & 4.9 & 3.9 & $0.1-17.4$ & 1.08 & $4 \cdot 28$ & 3.47 & I I $\cdot 37$ & $3 \cdot 47$ & $0.77 \dagger$ \\
\hline h.s. & $\mathrm{M}_{42}$ & 143 & $13 \cdot 5$ & 13.9 & $9 \cdot 2-19 \cdot 9$ & -0.07 & - & - & 0.78 & $14 \cdot 36$ & 0.05 \\
\hline
\end{tabular}

$\bar{x}_{g}$, Mean titre of progeny with green conidia; $\bar{x}_{y}$, Mean titre of progeny with yellow conidia.

* See Table 4 for isolate nos.

$\uparrow$ Significantly different from zero.

¥ Significantly smaller than $\bar{x}_{g}$.

In all crosses segregating for conidial colour, progeny with yellow conidia had a lower mean titre than those with green (Table 6), and this difference was significant in four cases (M2, M3, M4 and M40). Although the six yellow mutations involved were not tested for allelism with the $y A$ locus it is likely that they all involve this gene since it is the only one reported to produce the yellow phenotype (Clutterbuck, 1972).

\section{DISCUSSION}

Variation and inheritance of penicillin production. Wild-type isolates of $A$. nidulans differ in their ability to produce penicillin. Three isolates gave no detectable antibiotic activity, while the highest producing isolate (Birmingham No. I09) gave a titre of $14 \cdot 4 \pm \mathrm{I} \cdot 45 \mathrm{u} / \mathrm{ml}$. These results are similar to those of Holt \& Macdonald (I968a) although these authors 


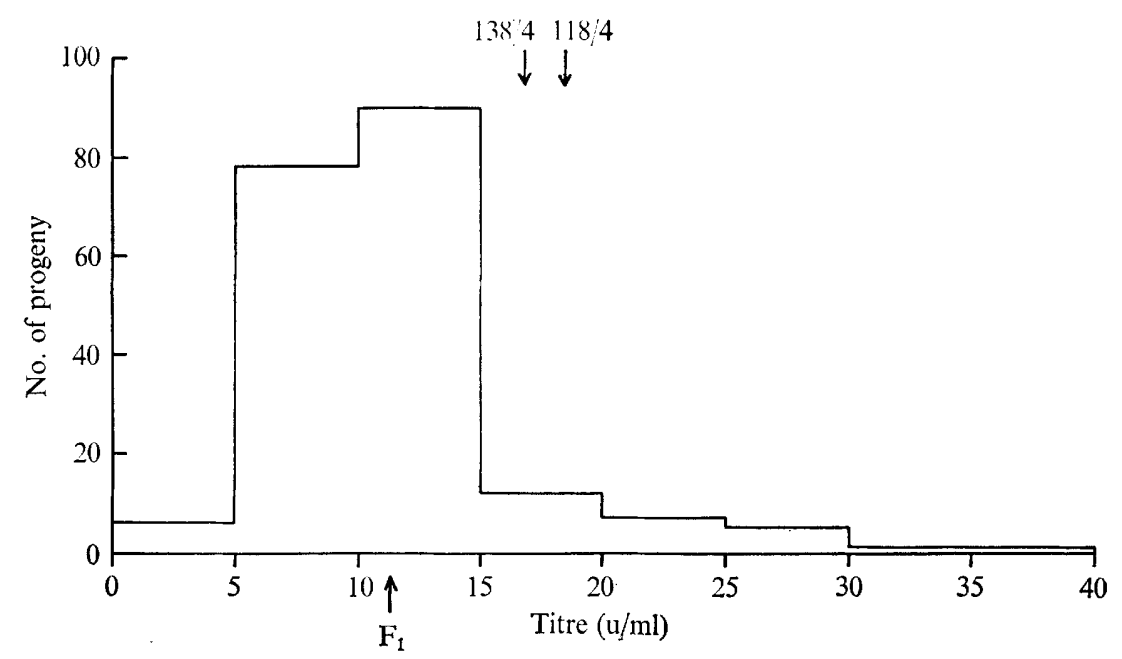

Fig. 3. Distribution of penicillin titres among 200 progeny from the cross $118 / 4$ (ribo-02, $y-09) \times$ I38/4 (w-06, meth-05). $\uparrow$, Progeny mean titre; $\downarrow$, parental titres. Contrast the asymmetrical distribution and the difference between the parental and progeny means with those in Fig. 2. Data from Holt \& Macdonald (I968 $b$ ), by kind permission of the authors.

obtained up to $20 \mathrm{u} / \mathrm{ml}$ from certain strains. Since the present isolates represent a $50 \%$ sample of those examined by Holt \& Macdonald (1968a) this discrepancy presumably reflects minor differences in the experimental conditions. In an investigation of antibiotic production in $A$. nidulans by Dulaney ( 1947 ), a maximum yield of $50 \mathrm{u} / \mathrm{ml}$ was obtained with one isolate. In this case the fermentation and assay conditions differed in a number of respects from those used here.

Four of the eight crosses showed genetic variation for penicillin titre. That this variation reflects the segregation of genetic differences present in the wild isolates and not mutations induced by the single u.v. treatment is indicated by (i) the observations of significant variation after removal from the analysis of any effects associated with the induced yellow marker, (ii) the rarity of u.v.-induced mutations affecting penicillin titre (Macdonald, Holt \& Ditchburn, 1972) and (iii) the observed relationship between the magnitude of the genetic variations and the heterokaryon compatibility of the parents. The continuous nature of the progeny distributions (Fig. 2) suggests that this natural variation is polygenically determined. Comparisons of the range of the $\mathrm{F}_{1}$ progeny distributions and the value of $\sigma_{G}{ }^{2}$ indicate that five or more effective factors are segregating in each of the crosses with a significant genetic component. Epistatic variation was detected in only one of the four segregating crosses, suggesting that the allelic differences present in wild-type isolates and affecting penicillin production act in an additive manner.

These results agree with the general findings of Holt \& Macdonald (1968 $b$ ) in indicating that wild-type isolates carry different alleles at a number of loci affecting penicillin yield and that these alleles can be recombined to give strains with either higher or lower titres than the parents. However, their published data for one cross between wild-type isolates and crosses of a strain carrying a titre-increasing mutation with two independent wild-type isolates (Holt \& Macdonald, $1968 \mathrm{~b}$ ) indicate the presence of large titre-increasing non-allelic interactions in the parents. Their results for the cross between wild-type isolates (Birmingham Nos. I 8 and 138 ) are reproduced as a frequency distribution in Fig. 3 which clearly shows 
that the majority of the progeny produced less penicillin than either parent (contrast with Fig. 2). This marked epistasis could be a property of these particular crosses. Alternatively, it may be attributed to the presence of auxotrophic markers in the parents and their segregating progeny. While the particular markers used individually had little effect in the background in which they were induced (Holt \& Macdonald, I968 b), it is possible that following recombination they may have interacted either with each other or with the new genetic backgrounds, or both, to produce the observed depression in titre. Auxotrophic markers were not used in the present work.

There is little published data on parasexual crosses in Penicillium chrysogenum for which similar analyses can confidently be carried out. Ball (1973) gave the titres of a small number of segregants from crosses between high-titre strains derived by mutation from QI 76 , and in all those crosses in which at least twelve segregants had been assessed for penicillin production the progeny mean was less than the parental mean, suggesting non-additive gene action.

With regard to natural variation for other quantitative characters in fungi, predominantly additive gene action, like that reported here for penicillin titre, has been found for radial growth rate, specific growth rate and growth yield in $A$. nidulans (Butcher, 1969; L. Handley, personal communication), linear growth rate in Aspergillus amstelodami (Caten, unpublished) and linear growth rate in monokaryons of Schizophyllum commune (Simchen, I966a). More complex gene action involving additive, dominance and epistatic effects has been found for a variety of characters in dikaryons of $S$. commune (Simchen, 1966 b), Collybia velutipes (Simchen, 1965) and Ustilago hordei (Emara, 1972).

The relationship between heterokaryon compatibility groups and penicillin yield. Grindle (1 $963 a, b)$ observed that heterokaryon-compatible isolates of $A$. nidulans are usually identical or extremely similar in their general colony morphology and radial growth rate, whereas incompatible isolates frequently differ for these characters. The phenotypic similarity of compatible isolates was further emphasized by an analysis of their response to a range of environments (Butcher, Croft \& Grindle, 1972). These observations suggested that compatible wild-type isolates have similar genotypes for the characters in question, while incompatible isolates are of different genotype. This was confirmed by the demonstration that crosses involving compatible isolates show considerably less variation for radial growth rate than those involving incompatible isolates (Jinks, Caten, Simchen \& Croft, I966). From their data, Holt \& Macdonald (1968a) suggested that the situation was similar for penicillin yield, although the number of isolates of known compatibility was too small to allow any definite conclusions to be drawn. More information on this question can be obtained from the present study.

The partitioning of the between-isolates variation in Table 2 clearly shows that, on average, compatible wild-type isolates are more alike in penicillin yield than incompatible isolates. If, as with radial growth rate (Jinks et al. 1966), this phenotypic similarity reflects underlying genetic similarity we would expect the progeny of crosses between compatible isolates to show less variation for penicillin titre than those between incompatible isolates. Of the three compatible crosses only one showed segregation with an average $\hat{\sigma}_{G}{ }^{2}$ of 3.43 , as compared with $7.7 \mathrm{I}$ for the four incompatible crosses, only one of which did not show segregation. In general, therefore, these data are consistent with those of Jinks et al. (1966). However, both Grindle (1963b) and Butcher et al. (1972) found isolates which clearly belonged to a particular h-c group and yet deviated in a number of ways from the majority of members of that group, suggesting that compatibility is not invariably associated with general phenotypic and genotypic similarity. In fact, it is difficult to see from the simple genetic determination of heterokaryon incompatibility (Caten, Butcher \& Croft, 1972) why 
it should be correlated with other characters. Segregating crosses between heterokaryoncompatible isolates and non-segregating crosses between heterokaryon-incompatible isolates might therefore be expected and two such crosses ( $\mathrm{MI}_{\mathrm{I}}$ and $\mathrm{M}_{3}$ ) were found.

Apart from these two crosses, heterokaryon-compatible isolates are of similar genotype with respect to their penicillin yield, while incompatible isolates have dissimilar genotypes for this character. That this situation applies for two such different characters as radial growth rate and production of a secondary metabolite further strengthens the argument that members of the same h-c group are, with occasional exceptions, nearly isogenic and may be clonally related (Butcher et al. 1972).

Breeding for penicillin production. Both the present results and those of Holt \& Macdonald ( $1968 b$ ) show that crosses between wild-type isolates can yield recombinants producing more penicillin than their parents. It should be possible, therefore, to derive high-titre strains from the pool of natural variability by conventional hybridization and selection procedures over a series of generations. The results of such a study will be described in a future report. From the present work, it can be concluded that to maximize the genetic variation in the base population for such a selection programme the initial parental isolates should be heterokaryon-incompatible. This conclusion is of considerable importance since initial parental isolates chosen purely on the basis of titre could easily be compatible, with consequent restriction of the available genetic variation. Such considerations illustrate the importance of background genetic information concerning an organism and of preliminary studies in any strain improvement programme.

We thank Glaxo Research Laboratories Ltd, Sefton Park, Stoke Poges, Buckinghamshire, for the provision of equipment and materials, and the Glaxo staff for their continued guidance and encouragement. One of us (M.J.M.) gratefully acknowledges a Science Research Council C.A.P.S. Studentship. This work was in part supported by a grant from the Science Research Council.

\section{REFERENCES}

BALL, C. (1973). Improvement of penicillin productivity in Penicillium chrysogenum by recombination. In Genetics of Industrial Microorganisms, pp. 227-237. Edited by Z. Vanek, Z. Hostalek and J. Cudlin. Prague: Academia.

Brownlee, K. A., Loraine, P. K. \& Stephens, J. (1949). The biological assay of penicillin by a modified plate method. Journal of General Microbiology 3, 347-352.

BuTCHER, A. C. (1968). The relationship between sexual outcrossing and heterokaryon incompatibility in Aspergillus nidulans. Heredity 23, 443-453.

Butcher, A.C. (I969). Non-allelic interactions and genetic isolation in wild populations of Aspergillus nidulans. Heredity 24, $62 \mathrm{I}-63 \mathrm{I}$.

Butcher, A. C., CROFT, J. \& GRINDle, M. (1972). Use of genotype-environmental interaction analysis in the study of natural populations of Aspergillus nidulans. Heredity 29, 263-283.

Caten, C. E., Butcher, A. C. \& Croft, J. H. (1972), Genetical control of heterokaryon formation in Aspergillus. Microbial Genetics Bulletin 34, I6.

CLUTTERBUCK, A. J. (1972). Absence of laccase from yellow-spored mutants of Aspergillus nidulans. Journal of General Microbiology 70, 423-435.

Dorn, G. (1967). A revised map of the eight linkage groups of Aspergillus nidulans. Genetics 56, 619-63I.

Dulaney, E. L. (1947). Penicillin production by the Aspergillus nidulans group. Mycologia 39, 582-586.

EmARA, Y. A. (1972). Genetic control of aggressiveness in Ustilago hordei. I. Natural variability among physiological races. Canadian Journal of Genetics and Cytology 14, 919-924.

Foster, J. W. \& Karrow, E. O. (1945). Microbiological aspects of penicillin. VIII. Penicillin from different fungi. Journal of Bacteriology 49, 19-29.

GRINDLE, M. (1963a). Heterokaryon compatibility of unrelated strains in the Aspergillus nidulans group. Heredity 18, 191-204. 
Grinde, M. (1963b). Heterokaryon compatibility of closely related wild isolates of Aspergillus nidulans. Heredity 18, 397-405.

Holt, G. \& MacDonald, K. D. (I968a). Penicillin production and its mode of inheritance in Aspergillus nidulans. Antonie van Leeuwenhoek 34, 409-416.

HoLt, G. \& MACDONALD, K. D. (1968b). Isolation of strains with increased penicillin yield after hybridisation in Aspergillus nidulans. Nature, London 219, 636-637.

Jinks, J. L., CATEN, C. E., SimChen, G. \& Croft, J. H. (I966). Heterokaryon incompatibility and variation in wild populations of Aspergillus nidulans. Heredity 21, 227-239.

KäFER, E. (I958). An 8-chromosome map of Aspergillus nidulans. Advances in Genetics 9, 105-145.

LeEs, K. A. \& TootiLl, J. P. R. (I955). Microbiological assay on large plates. I. General considerations with particular reference to routine assay. Analyst 8o, 95-110.

Macdonald, K. D., Holt, G. \& Ditchburn, P. (1972). The genetics of penicillin production. In Proceedings IV International Fermentation Symposium: Fermentation Technology Today, pp. 25I-257. Osaka: Society for Fermentation Technology.

Macdonald, K. D., Hutchinson, J. M. \& Gillett, W. A. (1963). Isolation of auxotrophs of Penicillium chrysogenum and their penicillin yields. Journal of General Microbiology 33, 365-374.

MATHER, K. \& Jinks, J. L. (I97I). Biometrical Genetics, 2nd edn. London: Chapman and Hall.

PonteCorvo, G. \& KäFER, E. (1958). Genetic analysis based on mitotic recombination. Advances in Genetics 9, 7 I-104.

Pontecorvo, G., Roper, J. A., Hemmons, L. M., Macdonald, K. D. \& Bufton, A. (I953). The genetics of Aspergillus nidulans. Advances in Genetics 5, I4I-253.

RAPER, K. B. \& FenNel, D. I. (1965). The Genus Aspergillus. Baltimore: Williams and Witkins.

ROBERTs, C. F. (1969). Silica gel stock cultures of Aspergillus nidulans. Aspergillus Newsletter 10, 29.

SimCHEN, G. (1965). Variation in a dikaryotic population of Collybia velutipes. Genetics 5I, 709-721.

Simchen, G. (I966a). Monokaryotic variation and haploid selection in Schizophyllum commune. Heredity 2I, $24 \mathrm{I}-263$.

SiMCHEN, G. (1966 b). Fruiting and growth rate among dikaryotic progeny of single wild isolates of Schizophyllum commune. Genetics 53, I I5I-II 65.

SNEDECOR, G. W. \& Cochran, W. G. (1967). Statistical Methods, 6th edn., pp. 289-29o. Iowa State University Press. 